\title{
İş Sağlığı ve Güvenliği Kültürü Ölçeği; Geçerlik ve Güvenirlik Çalışması
}

\author{
Zeynep Feride Olcay ${ }^{{ }^{*}}$ \\ 1* İstanbul Aydın University, Anadolu Bil Vocational School, Departmant of Occupational Health and Safety, İstanbul, Turkey, (ORCID: 0000-0001-5720-7350), \\ zeynepolcay@aydin.edu.tr.
}

(İlk Geliş Tarihi 8 Şubat 2021 ve Kabul Tarihi 10 Nisan 2021)

(DOI: 10.31590 /ejosat.892845)

\begin{abstract}
ATIF/REFERENCE: Olcay, Z. F. (2021). X. İş Sağlığı ve Güvenliği Kültürü Ölçeği; Geçerlik ve Güvenirlik Çalışması. Avrupa Bilim
\end{abstract} ve Teknoloji Dergisi, (23), 678-685.

Öz

Bu çalışma, iş sağlığı ve güvenliği (İSG) kültürünü değerlendirmek amaçlı kullanılabilecek bir ölçek geliştirmek adına metodolojik olarak gerçekleştirilmiştir. Çalışmanın örneklemini İstanbul il sınırları içinde konut inşaat projelerinde çalışan 359 çalışan oluşturmaktadır. 405 adet anket formu elden dağıtılmış ve toplanmıştır. Formların 359 tanesi eksiksiz doldurulduğundan çalışmada 359 anket formu analiz edilmiştir. Ölçeğin kapsam geçerliliği için İSG konusunda uzmanların görüşleri alınmıştır. Çalışmanın amacı doğrultusunda, ölçme aracının yapı geçerliğini ortaya koymak için açımlayıcı ve doğrulayıcı faktör analizi gerçekleştirilmiştir. Ölçeğin ve ölçek faktörlerinin iç tutarlılığa bağlı güvenirliğini belirlemek için Cronbach alfa katsayıları hesaplanmıştır. Ölçek faktörleri arasındaki ilişkileri incelemek için Pearson korelasyon katsayıları hesaplanmıştır. Ölçeğin ayırt edicilik düzeyini belirlemek için ise \%27'lik alt ve üst grupta bulunan katılımcıların ölçek maddelerinden almış olduğu puanlar bağımsız örneklem t testi ile karşılaştırılmıştır. SPSS 25.0 ve AMOS 24.0 istatistik paket programları kullanılarak analizler gerçekleştirilmiştir. İSG Kültürü Ölçeğinin üç faktörlü, aynı zamanda geçerli ve güvenilir bir yapıya sahip olduğu belirlenmiştir.

Anahtar Kelimeler: İşçi sağlığı ve iş güvenliği, iş sağlığı ve güvenliği kültürü, güvenlik kültürü.

\section{Occupational Health and Safety Culture Scale; Validity and Reliability Study}

\begin{abstract}
This study is carried out methodologically in order to develop a scale that can be used to evaluate occupational health and safety culture. The sample of the study consists of 359 employees working in different business groups working in housing construction projects within the provincial borders of Istanbul. 405 questionnaires are handed out and related answers are collected. To ensure content validity of the scale, the opinions of experts on occupational health and safety are used. In accordance with purpose of the study, exploratory and confirmatory factor analysis is performed to find out validity of the measuring tool. Cronbach alpha coefficients are calculated to determine the reliability of the scale and scale factors based on internal consistency. Pearson correlation coefficients are calculated to examine the relationships between scale factors. In order to determine the discrimination level of the scale, the scores of the participants in the lower and upper groups of $27 \%$ obtained from scale items are compared through independent sample t test. SPSS 25.0 and AMOS 24.0 statistical package programs are used in the calculations regarding the analysis of the data. According to results of the analysis, It has been determined that the Occupational Health and Safety Culture Scale has a three-factors, at the same time, valid and reliable structure.
\end{abstract}

Keywords: Worker's health and work safety, Occupational health and safety culture, Safety culture

*Sorumlu Yazar: zeynepolcay@aydin.edu.tr 


\section{Giriş}

Dünyada ve ülkemizde çalışma hayatının en önemli sorunlarından birisi yaşanan iş kazalarıdır. Çalışma ortamında iş kazalarının sayısını azaltmak için gerek emniyetsiz durum, gerekse emniyetsiz davranışları ortadan kaldırmak gerekmektedir. Güvenlik kültürü kavramı, özellikle son yıllarda ISG konusunda yapılan çalışmalarda iş kazalarının oluşumunu engellemek konusunda üzerinde önemle durulan bir kavram olmuştur. Sosyal Güvenlik Kurumu (SGK) 2019 yılı verilerine göre; ülkemizde iş kazaları sonucu hayatını kaybeden sigortalı çalışanların sayısı 1.149'dur. Bunun yanında SGK 2019 kayıt bilgilerinde 4a sigorta kapsamında çalışanlar kişilerin yaşadığı iş kazası sayısı 422.463'dir (SGK, 2019). 2012 yılında 6331 Sayılı ISG Kanunu'nun yürürlüğe girmesine rağmen iş kazası sayılarında her yıl bir artış kaydedilmiş olsa da, bu sayı 2019 yılında azalmıştır. Yine de ülkemizde yaşanan iş kazaları sayıları ve özellikle ölümlü iş kazaları sayıları azımsanamayacak kadar fazladır.

İş güvenliği kavramı, çalışanların iş sahalarında kendilerine verilen görevleri yerine getirirken meydana gelen tehlikelerden, yapılan iş dolayısıyla oluşan endüstri kirliliğinden, fiziksel ve psikolojik olarak zarar görmemeleri için alınması gereken tüm önlemleri kapsayan çalışmalar olarak tanımlanabilir (Balkır, 2012). İş sağlığı ise tüm çalışanları fiziksel, sosyal ve psikolojik anlamda en iyi seviyeye taşımak, bu seviyenin devamlılığını, sürekliliğini bozacak etkenleri önlemeyi, çalışanların yeteneklerine uygun işlere yerleştirmeyi amaçlayarak yapılacak olan işin çalışanlara, çalışanların ise yaptıkları işle eşgüdümünü sağlamayı amaçlamış bir bilim dalı olarak açıklanmıştır (Uslu, 2014).

İSG, çalışanların işe bağlı tehlike ve risklerden arınmış olarak çalışmalarını temin eder. Bu anlamıyla, güvenlikli ve sağlıklı bir çalışma çevresi sağlanması, çalışanlar açısından önemli bir ihtiyaç şeklinde nitelendirilebilir (Demircioğlu ve Centel, 2003).

Dünya Sağlık Örgütü (WHO) ve Uluslararası Çalışma Örgütü (ILO) İş Sağlığı Ortak Komitesi iş sağlığı alanındaki hedeflerini şu şekilde tanımlamıştır: "İş sağlığı, hangi sektörde olursa olsunlar, görev tanımı farketmeksizin tüm çalışanların sosyal, zihinsel ve fiziksel iyilik halinin en üst düzeyde tutulmasını; çalışma ortamının neden olduğu sağlık sorunlarının engellenmesini; sağlığına zarar veren işlerle ilgili tehlike ve risklerden çalışanların korunmasını; çalışanların fizyolojik ve fiziksel yeteneklerine uygun işlerde ve çalışma ortamlarında çalıştırılmasını; kısaca işin çalışanlara, çalışanların da yaptıkları işe uyumlu hale getirilmesini amaçlamaktadır (Alli, 2001).

Özetle İSG, iş kazalarının önün geçebilmek ve oluşan kazalarda kaza seviyesini en alt seviyeye düşürmek için yapılması gereken ve henüz iş kazaları gerçekleşmeden önce önleyici tedbirleri almaktır. Bu bağlamda, yaşanan iş kazalarının yaklaşık olarak \%95 gibi önemli bir bölümünün "insan” kaynaklı olması, yaşanan iş kazalarında insan etkeninin daha geniş açıdan değerlendirilmesi gerekliliğini ortaya koymaktadır. İş kazalarının yaşanmasında büyük bir oransal değere sahip olan, güvensiz ya da emniyetsiz davranış olarak nitelendirilen ve güvensiz durumların ortaya çıkmasında da etkili olan insan faktörü dikkate alındığında (Sakallı, 2019) özellikle son yıllarda iş kazalarının azaltılmasında büyük önem arz eden kavramlardan biri de “güvenlik kültürü” kavramıdır. (Dursun, 2012).

\section{Materyal ve Metot}

\subsection{Güvenlik Kültürü}

Güvenlik kültürü, ilk defa 1986 yılında Çernobil'de meydana gelen nükleer kaza felaketinden sonra OECD nükleer ajansı tarafından kullanılmış olan bir kavramdır. Güvenlik kültürü kavramına, Çernobil'de meydana gelen nükleer felaketin olası sebeplerinin araştırıldığı ve sorgulandığı bir raporda yer verilmiştir. $\mathrm{Bu}$ raporda ve diğer önemli kazaların yaşandığı olayların raporlarında, kazaların yaşanmasında, en önemli faktörün zayıf ve düşük bir güvenlik kültür düzeyi olduğu görülmektedir (Cox ve Flin, 1998).

Güvenlik kültürü kavramı her geçen gün daha fazla önem kazanmaktadır. Fakat güvenlik kültürünün uygulanabilir bir hale gelmesi çok kolay değil hatta mümkün değildir. Bilim alanı olarak çelişkili tanımlar ve anlayışlar içermektedir (Guldenmund, 2000).

Literatürde birbirinden farklı güvenlik kültürü tanımları yer almaktadır. Güvenlik kültürü kavramıyla ilgili bazı tanımlar aşağıda yer almaktadır;

İngiliz Sanayi Konfederasyonu 1991 yılında güvenlik kültürünü " tüm organizasyon üyelerinin risk, kazalar ve hastalıklar hakkında paylaştığı fikirler ve inançlar " olarak tanımlamıştır (Cooper, 2000).

“Güvenlik kültürü, genellikle inançların ve değerlerin özellikle sağlık ve güvenlik konularına atıfta bulunduğu organizasyon kültürünün bir alt kümesi olarak görülür" (Clarke, 1999).

' 'Güvenlik kültürü, özellikle organizasyonel kültürün tutum ve davranışlarını etkileyen ve organizasyondaki güvenlik düzeyinde etkisi olan taraflar ve bileşenler" olarak anlaşılmaktadır (Hale, 2000).

Güvenlik kültürü kavramı farklı olarak ifade edilmiş olsa da, konunun önemi ve geçerliliği herkes tarafından önemsenmektedir. Güvenlik kültürünün her geçen gün daha da önem kazanmasına rağmen, inşaat sektörü çok uzun yıllar zayıf bir güvenlik kültürü ile etiketlenmiştir (Misnan ve Mohammed, 2007). Güvenlik kültürü, birçok sektörde ölüm ve yaralanmaların azaltılmasında önemli bir etkiye sahiptir (Olcay, Temur \& Sakallı, 2021).

SGK verilerine göre; 2019 yılında inşaat sektöründe istihdamın \%35 oranında azalmasıyla, yaşanan iş kazaları \%38 oranında azalmıştır. İnşaat sektöründe 2019 yılında ölümlü iş kazaları da \%35 oranında azalmış olmasına rağmen, 2019 yılı ülkemizde ölümlü iş kazaları en fazla yine inşaat sektöründe yaşanmıştır. Günde yaklaşık 176 iş kazası, iş kazası sonucu üç işçi hayatını kaybetmekte, beş işçi ise yaralanmaktadır Bu sonuçlara bakıldığında, sadece teknik çalışmalar ya da hukuki düzenlemelerin, iş kazalarını önleme konusunda yeterli olmadığını göstermektedir (İSİG Meclisi, 2020). Türkiye'de 2012-2019 yılları arasında inşaat sektöründe 3517 ölümlü kaza meydana gelmiş (Olcay ve diğ., 2021) ve yapılan birçok çalışmada Türkiye'de güvenlik kültür düzeyinin zayıf olduğu dile getirilmiştir (Temur \& Mertoğlu, 2019; Olcay ve diğ., 2021).

Ülkemizde inşaat sektöründe İSG konusuna özellikle son yıllarda daha fazla önem verildiği gerçeği olsa bile, SGK verilerinden de anlaşılacağı gibi inşaat sektörü çalışanları her yıl yaşanan yüksek sayılardaki iş kazaları sonucu yaşamlarını kaybetmekte, yaralanmalar veya hastalıklardan dolayı geçici ya 
da sürekli iş göremezlik gibi sorunlarla karşı karşıya kalmaktadırlar. Ayrıca, ISG konusunda yeterli seviyeye ulaşamayan ülkelerin ekonomileri de olumsuz yönde etkilenmektedir (Öztürk ve Caner Akın, 2021). Bu durumdan dolayı iş kazası ve meslek hastalıkları sayılarının azalması için toplum olarak İSG konusunda bilinçlenme ve güvenlik kültürü büyük arz etmektedir. Bu durumlardan dolayı çalışmada, özellikle eğitim seviyesinin diğer sektörlere göre daha düşük olduğu çalışanların bulunduğu inşaat sektöründe çalışanların İG kültürünü ölçmek adına bir ölçek geliştirilmeye çalışmıştır.

\subsection{Verilerin İstatistiksel Analizi}

Araştırmanın evrenini İstanbul'da konut projeleri inşaatında çalışanlar oluşturmaktadır. Konut projelerinde toplamda 405 adet anket formu elden dağıtılmış ve toplanmıştır. Formların 359 tanesi eksiksiz doldurulduğundan çalışmada 359 anket formu analiz edilmiştir. Anket soruları 7'li Likert ölçeği kullanılarak değerlendirilmiştir. Anketi cevaplandıracak kişilerden her bir anket maddesine ne derece katılıp/katılmadıklarını belirtmeleri

için ölçekte yer alan " 1 : Kesinlikle katılmıyorum, 2:Katılmıyorum, 3:Kısmen Katılmıyorum, 4:Kararsızım, 5: Kismen Katıliyorum, 6: Katıliyorum, 7: Kesinlikle Katıliyorum' u" temsil etmektedir.

Çalışmanın amacı doğrultusunda, geliştirilmiş olan (İSG kültürü ölçeğinin), ölçme aracının yapı geçerliğini incelemek adına açımlayıcı ve doğrulayıcı faktör analizi gerçekleştirilmiştir. Ölçeğin ve ölçek faktörlerinin iç tutarlılığa bağlı güvenirliğini belirlemek için Cronbach alfa katsayıları hesaplanmıştır. Ölçek faktörleri arasındaki ilişkileri incelemek için Pearson korelasyon katsayıları hesaplanmıştır. Ölçeğin ayırt edicilik düzeyini belirlemek için ise \%27'lik alt ve üst grupta bulunan katılımcıların ölçek maddelerinden almış olduğu puanlar bağımsız örneklem t testi ile karşılaştırılmıştır. SPSS 25.0 ve AMOS 24.0 istatistik paket programları kullanılarak analizler gerçekleştirilmiştir.

\section{Araştırma Sonuçları ve Tartışma}

\subsection{Demografik özelliklere göre Analiz Sonuçları}

Tablo 1. Katılımcıların Tanımlayıcı Özelliklerine Göre Dă̆ılımı

\begin{tabular}{|c|c|c|c|}
\hline & & $\mathrm{F}$ & $\%$ \\
\hline \multirow{5}{*}{ Yaş } & $18-24$ & 85 & 23,7 \\
\hline & $25-34$ & 131 & 36,5 \\
\hline & $35-44$ & 89 & 24,8 \\
\hline & $45-54$ & 50 & 13,9 \\
\hline & 55 ve üzeri & 4 & 1,1 \\
\hline \multirow{2}{*}{ Cinsiyet } & Erkek & 347 & 96,7 \\
\hline & Kadın & 12 & 3,3 \\
\hline \multirow{2}{*}{ Medeni durumu } & Bekar & 161 & 44,8 \\
\hline & Evli & 198 & 55,2 \\
\hline \multirow{4}{*}{ Eğitim durumu } & İlköğretim & 228 & 63,5 \\
\hline & Ön lisans-Lisans & 23 & 6,4 \\
\hline & Lise & 106 & 29,5 \\
\hline & Mezuniyet yok & 2 & 0,6 \\
\hline \multirow{5}{*}{ Gelir düzey (TL) } & $2001-3000$ & 97 & 54,1 \\
\hline & $3001-4000$ & 135 & 37,6 \\
\hline & $4001-5000$ & 22 & 6,1 \\
\hline & $5001-6000$ & 2 & 0,6 \\
\hline & 6001 üzeri & 3 & 0,8 \\
\hline \multirow{2}{*}{ Çocuk var mı? } & Evet & 184 & 51,3 \\
\hline & Hayır & 175 & 48,7 \\
\hline \multirow{5}{*}{ İş tecrübesi } & $1-2 \mathrm{y} 11$ & 71 & 19,8 \\
\hline & $11-15 \mathrm{y} 1 \mathrm{l}$ & 52 & 14,5 \\
\hline & 16 y1l üzeri & 65 & 18,1 \\
\hline & $3-5$ y1l & 87 & 24,2 \\
\hline & $6-10$ y1l & 84 & 23,4 \\
\hline \multirow{2}{*}{ İSG eğitimi } & Evet & 349 & 97,2 \\
\hline & Hayır & 10 & 2,8 \\
\hline \multirow{2}{*}{ İş kazası } & Evet & 49 & 13,6 \\
\hline & Hayır & 310 & 86,4 \\
\hline \multirow{3}{*}{ Ramak kala } & Evet & 87 & 24,2 \\
\hline & Hayır & 272 & 75,8 \\
\hline & Toplam & 359 & 100,0 \\
\hline
\end{tabular}


Tablo 1 incelendiğinde;

Cinsiyet dağglımına göre; ankete katılan 359 çalışanın yüzde 96.7'sini erkek çalışanlar, yüzde 3,3'ünü kadınlar oluşturmaktadır.

Yaş dağılımına göre; ankete katılan 359 çalışanın, yüzde 23,7'si 18-24 yaş aralığında, yüzde 36,5'sı 25-34 yaş aralığında, yüzde 24,8'i 35-44 yaş aralığında, yüzde 13,9'u 45-54 yaş aralığında, yüzde 1,1 'i ise 55 yaş ve üzerindeki çalışanlardan oluşmaktadır.

Eğitim durumuna göre; ankete katılan 359 çalışanın yüzde 63.5'i ilköğretim mezunu, yüzde 5,4'ü lisans ve önlisans mezunu, yüzde 29.5 'i lise mezunu, yüzde 0,6'sının mezuniyeti yoktur.

İş kazası geçirme durumuna göre; ankete katılan 359 çalışandan yüzde 13,6'sı iş kaza geçirdiğini belirtmiş, yüzde 86,4'ü kaza geçirmediğini belirtmiştir.

\subsection{Açımlayıcı Faktör Analizi Sonuçları}

Açımlayıcı faktör analizi, birbiri ile ilişkili çok sayıda değişkeni bir araya getirerek, az sayıda kavramsal olarak anlamlı yeni değişkenler (faktörler) keşfetmeyi amaçlayan çok değişkenli bir analiz tekniğidir (Çokluk, vd., 2010). Faktör analizi yapılmadan önce örneklemin yeterli sayıda olup olmadığ1 ve aynı zamanda verilerin faktör analizi yapmak için uygun olup olmadığı araştırılmalıdır. Bunun için Kaiser-Meyer-Olkin (KMO) katsayısı hesaplanmış ve Barlett Sphericity testi uygulanmıştır (Field, 2013). Elde edilen sonuçlar örneklem sayısının yeterli olduğunu ve ölçek verilerinin faktör analizine uygun olduğunu göstermiştir $(\mathrm{KMO}=0,94>0,70 ;$ Barlett Sphericity $(\chi 2(276))=4704,39$; $\mathrm{p}<0,001)$.

Faktör çıkarma yöntemlerinden Temel Bileşenler Analizi yöntemi kullanılarak analiz gerçekleştirilmiştir. Analiz sürecinde faktör yükleri için kesim noktası 0,32 olarak belirlenmiştir (Tabachnick ve Fidell, 2007). Faktör analizi sonucunda öz-değeri birin üzerinde üç faktör tespit edilmiştir. Aynı zamanda, öz-değer faktör grafiğinde dördüncü noktadan sonraki bileşenlerin varyansa yaptıkları katkının hem küçük hem de yaklaşık olarak aynı olduğu gözlenmiştir. Bu sonuçlar dikkate alınarak faktör sayısının üç olmasına karar verilmiştir. Bir sonraki adımda ölçek maddeleri üç faktöre zorlanarak analiz gerçekleştirilmiştir. Maddelerin bulunduğu faktörleri daha belirgin hale getirmek için döndürme yöntemlerinden Varimax dik döndürme metodundan faydalanılmıştır. Faktör yükü kesim noktasının altında kalan bir madde $(\mathrm{m} 4)$ ve birden çok faktörde yüklenen binişik üç madde (m12, m13 ve m17) ölçekten tek tek çıkarılarak analiz tekrarlanmıştır. Nihai analiz sonucunda ölçekte 19 maddenin kaldığı gözlenmiştir. İSG Kültürü Ölçeğinin faktör yapısı Tablo 2a'da gösterilmiştir.

Tablo 2a. İşS Sağlı̆̆l ve Güvenliği Kültürü Ölçeğinin Faktör Yapısı

\begin{tabular}{|c|c|c|c|c|c|c|}
\hline \multirow{2}{*}{ Madde No } & \multicolumn{3}{|c|}{ Faktör Yükü } & \multirow{2}{*}{$\begin{array}{c}\text { Madde Ortak } \\
\text { Varyans1 }\end{array}$} & \multirow{2}{*}{ Öz-değer } & \multirow{2}{*}{$\begin{array}{c}\text { Açıklanan varyans } \\
(\%)\end{array}$} \\
\hline & 1 & 2 & 3 & & & \\
\hline $\mathrm{m} 11$ & 0,77 & 0,31 & $-0,10$ & 0,71 & \multirow{12}{*}{7,74} & \multirow{12}{*}{33,04} \\
\hline $\mathrm{m} 9$ & 0,77 & 0,19 & $-0,07$ & 0,63 & & \\
\hline $\mathrm{m} 10$ & 0,77 & 0,11 & $-0,10$ & 0,61 & & \\
\hline $\mathrm{m} 1$ & 0,75 & 0,11 & $-0,01$ & 0,57 & & \\
\hline $\mathrm{m} 23$ & 0,73 & 0,35 & $-0,21$ & 0,70 & & \\
\hline $\mathrm{m} 16$ & 0,70 & 0,23 & $-0,03$ & 0,54 & & \\
\hline $\mathrm{m} 22$ & 0,69 & 0,35 & $-0,23$ & 0,66 & & \\
\hline $\mathrm{m} 5$ & 0,68 & 0,31 & $-0,19$ & 0,60 & & \\
\hline $\mathrm{m} 2$ & 0,65 & 0,04 & 0,07 & 0,43 & & \\
\hline $\mathrm{m} 3$ & 0,65 & 0,23 & $-0,04$ & 0,47 & & \\
\hline $\mathrm{m} 14$ & 0,63 & 0,26 & 0,03 & 0,46 & & \\
\hline $\mathrm{m} 15$ & 0,60 & 0,13 & 0,12 & 0,39 & & \\
\hline $\mathrm{m} 20$ & 0,26 & 0,76 & $-0,07$ & 0,66 & \multirow{4}{*}{1,88} & \multirow{4}{*}{9,89} \\
\hline $\mathrm{m} 21$ & 0,28 & 0,71 & $-0,04$ & 0,59 & & \\
\hline m19 & 0,11 & 0,68 & 0,19 & 0,50 & & \\
\hline $\mathrm{m} 18$ & 0,34 & 0,65 & $-0,11$ & 0,62 & & \\
\hline $\mathrm{m} 8^{\mathrm{r}}$ & $-0,01$ & $-0,04$ & 0,82 & 0,67 & \multirow{3}{*}{1,29} & \multirow{3}{*}{6,81} \\
\hline $\mathrm{m} 7^{\mathrm{r}}$ & $-0,07$ & $-0,03$ & 0,77 & 0,61 & & \\
\hline $\mathrm{m} 6^{\mathrm{r}}$ & $-0,05$ & 0,06 & 0,68 & 0,48 & & \\
\hline
\end{tabular}

${ }^{\mathrm{r}}$ Ters maddeler

Faktör analizi sonucunda, birinci faktörde bulunan maddelerin faktör yüklerinin 0,60 ile 0,77 arasında, ikinci faktörde bulunan maddelerin 0,65 ile 0,76 arasında ve üçüncü faktörde bulunan maddelerin faktör yüklerinin ise 0,68 ile 0,82 arasında değer 
aldığ 1 gözlenmiştir. Üç faktörlü ölçek toplam varyansın \%57'sini açıklamıştır. Açıklanan varyansın \%50’yi geçmesi, toplam değişken varyansının yarısından fazlasının açıklandığını ve maddelerin temsil gücünün yüksek olduğunu göstermektedir
(Yaşlığlu, 2017). Birinci, ikinci ve üçüncü faktör sırasıyla genel iş güvenliği farkındalığı, ISG eğitimi-iletişim ve risk algısı olarak isimlendirilmiştir. İSG Kültürü Ölçeği üç faktörlü 19 önerme ile Tablo 2b'de yer almaktadır.

Tablo 2b. $\dot{I}_{S}$ Sağlı̆̆l ve Güvenliği Kültürü̈ Ölçeğinin Faktör Yapısı

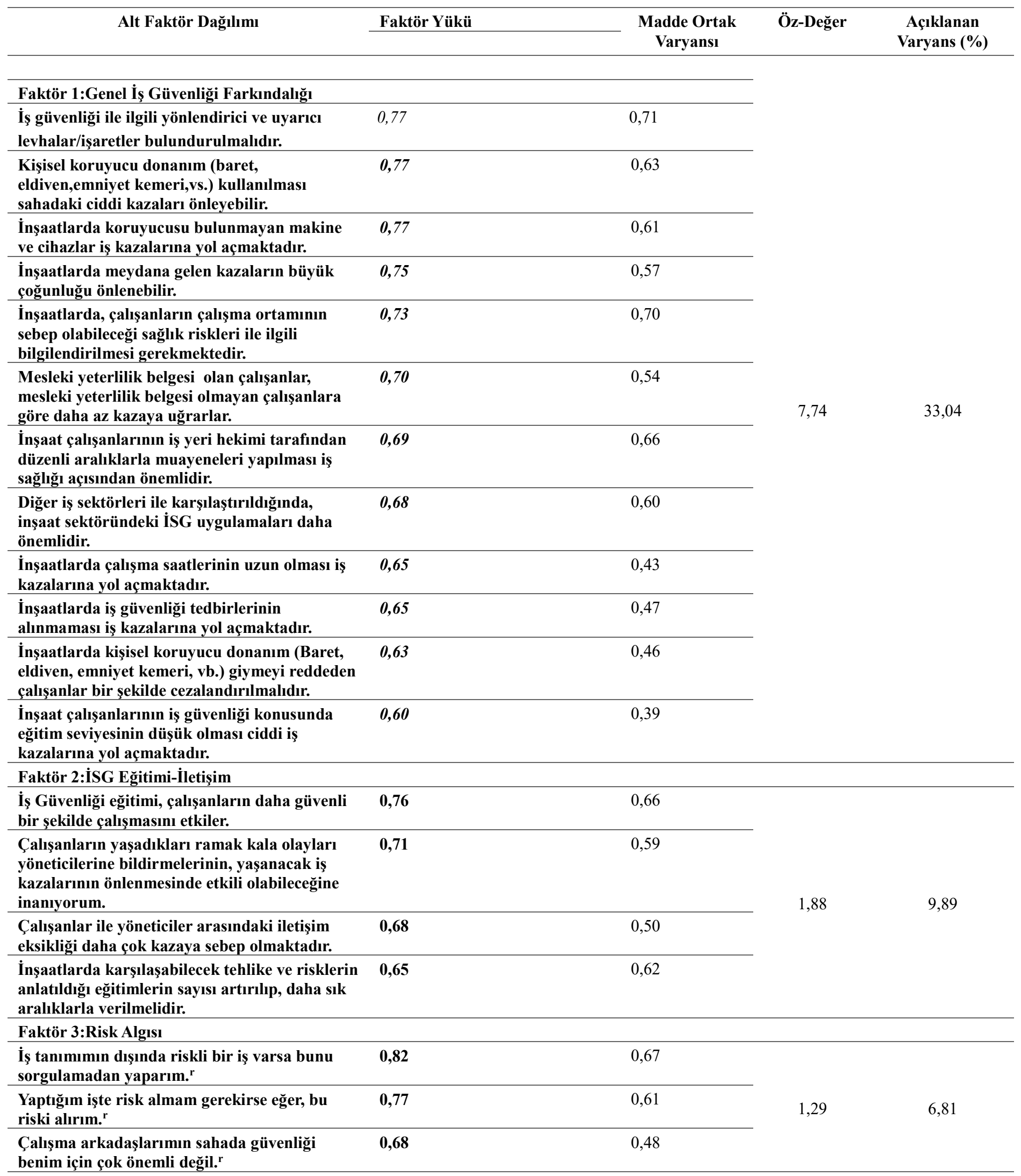

${ }^{\mathrm{r}}$ Ters maddeler 


\subsection{Doğrulayıcı Faktör Analizi Sonuçları}

Açımlayıcı faktör analizi sonuçları İş Güvenliği Kültürü Ölçeğinin üç faktörlü bir yapıya sahip olduğunu işaret etmiştir. Bir sonraki adımda, doğrulayıcı faktör analizi (DFA) uygulanmış ve ölçme aracının üç faktörlü yapısı test edilmiştir. DFA, önceden belirlenen faktörlerin yeterli düzeyde ilişkilere sahip olup olmadığı, faktörlerin birbirlerinden bağımsız olup olmadığı, hangi değişkenlerin hangi faktörlerle ilişkili olduğu ve faktörlerin modeli açıklamakta yeterli olup olmadığı hakkında bilgi vermektedir (Özdamar, 2004). Bu çalışmada, İSG Kültürü Ölçeğinin üç faktörlü yapısının toplanan veriler ile doğrulanıp doğrulanmadığını test etmek için DFA gerçekleştirilmiştir. Uyum değerlerini iyileştirmek için modifikasyon önerileri incelenerek değerlendirilmiştir. Önerilen modifikasyonların yapılmasının kikare değerine önemli ölçüde katkı sağlayacağı gözlenmiştir. Bu doğrultuda bazı maddelerin hata değerleri arasına korelasyon okları eklenmiştir (Şekil 1). Model için hesaplanan uyum değerleri Tablo 3'de yer almaktadır.

Tablo 3. Işs Să̆ll̆̆g ve Güvenliği Kültürü Ölçeğinin Ü̧̧ Faktörlü Yapısına Ait Uyum Değerleri

\begin{tabular}{|c|c|c|c|c|}
\hline Ölçüt & İyi Uyum & $\begin{array}{c}\text { Kabul } \\
\text { Edilebilir Uyum }\end{array}$ & Elde Edilen Değerler & Kaynak \\
\hline$\left(\chi^{2} / \mathrm{sd}\right)$ & $\leq 3$ & $\leq 4-5$ & 2,05 & Byrne, 1989 \\
\hline RMSEA & $\leq 0,05$ & $0,06-0,08$ & 0,05 & \multirow{2}{*}{ Browne ve Cudeck, 1993} \\
\hline SRMR & $\leq 0,05$ & $0,06-0,08$ & 0,04 & \\
\hline CFI & $\geq 0,95$ & $0,90-0,94$ & 0,95 & \multirow{2}{*}{ McDonald ve Marsh, 1990} \\
\hline TLI & $\geq 0,95$ & $0,90-0,94$ & 0,94 & \\
\hline GFI & $\geq 0,90$ & $0,89-0,85$ & 0,92 & Tanaka and Huba, 1985; \\
\hline AGFI & $\geq 0,90$ & $0,89-0,80$ & 0,90 & Jöreskog ve Sörbom, 1984 \\
\hline
\end{tabular}

Tablo 3 incelendiğinde, İSG Kültürü Ölçeğinin üç faktörlü yapısının toplanan veriler ile genel olarak iyi düzeyde uyum gösterdiği ve ölçeğin üç faktörlü yapısının doğrulandığ anlaşılmaktadır.

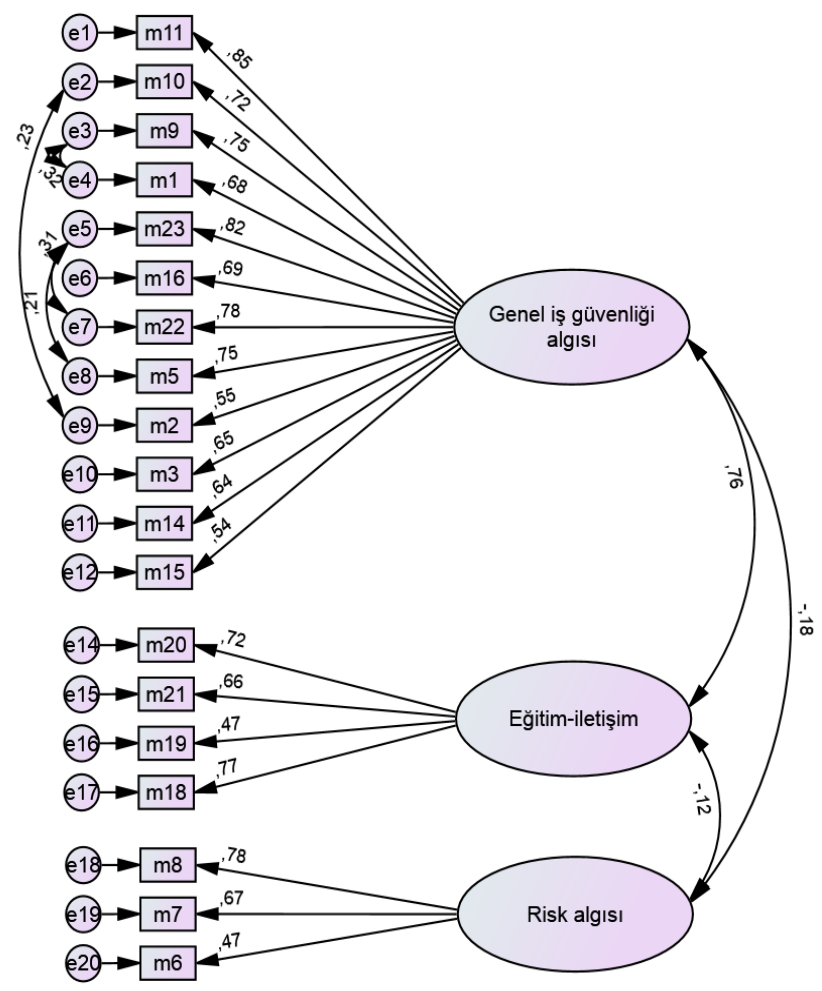

Şekil 1. İ̧S Să̆lı̆̆l ve Güvenliği Kültürü Ölçeğinin DFA Diyagramı, $\chi 2=296,92 ; s d=145 ; p<0,001$
DFA sonucunda ölçekte bulunan maddelerin faktör yükleri 0,47 ve 0,85 arasında değerler almıştır. Test edilen üç faktörlü model Şekil 1'de gösterilmiştir. Modelde gösterilen tüm yol katsayıları (faktör yükleri) düzeyinde istatistiksel olarak anlamlı bulunmuştur $(\mathrm{p}<0,001)$.

\subsection{Güvenirlik Analizi Sonuçları}

ISG Kültürü Ölçeğinin güvenirliğini belirlemek amacıyla ölçek faktörlerinin her biri için Cronbach Alfa katsayıları hesaplanmıştır. 0,60-0,80 arasında olan alfa katsayıları ölçeğin oldukça güvenilir olduğunu ve 0,81-1,00 arasındaki alfa katsayıları ise ölçeğin yüksek derecede güvenilir olduğunu göstermektedir (Özdamar, 2004). Ölçek faktörleri için hesaplanan Alfa katsayıları Tablo 4'te gösterilmiştir.

Tablo 4. İşSağlı̆̆l ve Güvenliği Kültürü Ölçeği Faktörlerine Ait Alfa Katsayıs

\begin{tabular}{lcc}
\hline Faktörler & Madde sayısı & Cronbach Alfa \\
\hline Genel iş güvenliği & 12 & 0,92 \\
farkındalığı & 4 & 0,75 \\
İSG Eğitimi-iletişim & 3 & 0,66 \\
Risk algısı & 19 & 0,89 \\
Ölçeğin geneli & \\
\hline
\end{tabular}

Tablo 4 incelendiğinde, genel iş güvenliği farkındalığ faktörü için hesaplanmış olan alfa katsayısının 0,92 İSG eğitimi-iletişim faktörü için hesaplanan alfa katsayısının 0,75 risk algısı faktörü için hesaplanan alfa katsayısının ise 0,66 ve ölçeğin geneli için hesaplanan alfa katsayısının 0,89 olduğu anlaşılmaktadır. Elde edilen katsayılar, İSG Kültürü Ölçeğinin ve ölçek faktörlerinin iç tutarlılığa bağlı güvenirliklerinin yeterli düzeyde olduğunu işaret etmiştir.

\section{5.Ölçek Faktörleri Arasındaki İlişkilerin İncelenmesi}

Ölçek boyutları arasındaki ilişkileri hesaplamak için Pearson korelasyon katsayıları hesaplanmıştır. Elde edilen sonuçlar Tablo 
4'te gösterilmiştir. 0 ile $\pm 0,30$ arasındaki katsayılar düşük ilişkileri, $\pm 0,31$ ile $\pm 0,70$ arasındaki katsayılar orta düzey ilişkileri, $\pm 0,71$ ile \pm 1 arasındaki katsayılar ise yüksek düzey ilişkileri göstermektedir (Büyüköztürk, 2007).

Tablo 5. Ölçek Faktörleri Arasındaki İlişkilere Ait Pearson Korelasyon Katsayılart

\begin{tabular}{lccccc}
\hline Değişkenler & Ort & Ss & 1. & 2. & 3. \\
\hline 1. Genel iş güvenliği & 5,79 & 1,32 & 1 & & \\
$\quad$ farkındalığ 1 & & & & \\
2. İSG Eğitimi-iletişim & 5,55 & 1,44 & $0,61^{* *}$ & 1 & \\
3. Risk algısı & 2,59 & 1,70 & $-0,14^{* *}$ & $-0,04$ & 1 \\
${ }^{* *} \mathrm{p}<0,01 ; \mathrm{N}=359$ & & & & &
\end{tabular}

Tablo 5 incelendiğinde, ölçek faktörleri arasında düşük ve orta düzeyde pozitif ve negatif yönlü ilişkilerin bulunduğu anlaşılmaktadır. Genel iş güvenliği farkındalığı arttıkça İSG eğitimi-iletişim $(r=0,61 ; p<0,01)$ artmakta, risk algısı $(r=-0,14$; $\mathrm{p}<0,01)$ azalmaktadır. Ayrıca, ISG eğitimi-iletişim arttıkça risk algısının azaldığı gözlenmiştir $(r=-0,04 ; \mathrm{p}>0,05)$.

\subsection{Ayırt Edici Geçerlik Analizi Sonuçları}

Ayırt edici geçerlik analizi için İSG Kültürü Ölçeğinin faktörlerinden elde edilen toplam puanlar en yüksek puandan en düşüğe doğru sıralanmıştır. Siralamanın her iki ucunda bulunan $\% 27^{\prime}$ lik en yüksek puanlı katılımcılar üst grup, \%27'lik en düşük puanlı katılımcılar ise alt grup olarak tanımlanmıştır. Alt ve üst grubun ölçek maddelerinin her birinden aldığı puan ortalamaları karşılaştırılarak incelenmiştir. Elde edilen sonuçlar ayırt edici geçerlik hakkında bilgi vermektedir (Tavşancıl, 2005). Alt ve üst grupların puan ortalamaları bağımsız örneklem t testi ile karşılaştırılarak incelenmiştir. Elde edilen sonuçlar Tablo 6' da yer almaktadır.

Tablo 6. IŞS Sağlığl ve Güvenliği Kültürü Ölçeğinin Madde Analizi Sonuçları

\begin{tabular}{|c|c|c|c|c|c|c|}
\hline \multirow{2}{*}{ Faktör } & \multirow{2}{*}{ Madde No } & \multicolumn{2}{|c|}{ Alt Grup (n=97) } & \multicolumn{2}{|c|}{ Üst Grup (n=97) } & \multirow[b]{2}{*}{$\mathrm{t}$} \\
\hline & & Ort & Ss & Ort & Ss & \\
\hline \multirow{12}{*}{$\begin{array}{l}\text { Genel iş } \\
\text { güvenliği } \\
\text { farkındalığ1 }\end{array}$} & $\mathrm{m} 1$ & 4,26 & 2,29 & 6,71 & 0,79 & $9,98^{* *}$ \\
\hline & $\mathrm{m} 2$ & 4,31 & 2,15 & 6,34 & 1,27 & $8,00^{* *}$ \\
\hline & $\mathrm{m} 3$ & 3,78 & 2,39 & 6,82 & 0,68 & $12,04^{* *}$ \\
\hline & $\mathrm{m} 5$ & 4,22 & 2,32 & 6,81 & 0,63 & $10,64^{* *}$ \\
\hline & $\mathrm{m} 9$ & 4,39 & 2,32 & 6,91 & 0,29 & $10,59^{* *}$ \\
\hline & $\mathrm{m} 10$ & 4,43 & 2,30 & 6,82 & 0,43 & $10,08^{* *}$ \\
\hline & $\mathrm{m} 11$ & 4,57 & 2,28 & 6,95 & 0,22 & $10,23^{* *}$ \\
\hline & $\mathrm{m} 14$ & 3,60 & 2,29 & 6,51 & 1,28 & $10,94^{* *}$ \\
\hline & $\mathrm{m} 15$ & 3,95 & 2,21 & 6,62 & 1,04 & $10,76^{* *}$ \\
\hline & $\mathrm{m} 22$ & 4,27 & 2,35 & 6,93 & 0,26 & $11,09^{* *}$ \\
\hline & $\mathrm{m} 23$ & 4,35 & 2,29 & 6,90 & 0,31 & $10,85^{* *}$ \\
\hline & $\mathrm{m} 16$ & 4,30 & 2,24 & 6,84 & 0,40 & $10,97^{* *}$ \\
\hline \multirow{4}{*}{$\begin{array}{l}\text { İSG Eğitimi- } \\
\text { iletişim }\end{array}$} & $\mathrm{m} 18$ & 3,56 & 2,12 & 6,55 & 0,94 & $12,70^{* *}$ \\
\hline & $\mathrm{m} 19$ & 4,34 & 2,17 & 6,28 & 1,46 & $7,31^{* *}$ \\
\hline & $\mathrm{m} 20$ & 4,31 & 2,27 & 6,87 & 0,34 & $10,95^{* *}$ \\
\hline & $\mathrm{m} 21$ & 4,16 & 2,24 & 6,66 & 0,89 & $10,20^{* *}$ \\
\hline \multirow{3}{*}{ Risk alg1sı } & $\mathrm{m} 6$ & 3,72 & 2,38 & 1,77 & 1,96 & $6,22^{* *}$ \\
\hline & $\mathrm{m} 7$ & 3,46 & 2,24 & 1,44 & 1,30 & $7,70^{* *}$ \\
\hline & $\mathrm{m} 8$ & 3,07 & 2,16 & 1,23 & 0,88 & $7,78^{* *}$ \\
\hline
\end{tabular}

${ }^{* *} \mathrm{p}<0,01$

Tablo 6 incelendiğinde, alt ve üst grupların her bir maddeden aldığı puan ortalamaları arasında anlamlı bir farklılık olduğu anlaşılmaktadır $(p<0,01)$. Üst grubun genel iş güvenliği farkındalığı ve İSG eğitimi-iletişim faktörlerinde bulunan maddelerin her birinden aldığı puan ortalamaları, alt grubun puan ortalamalarından anlamlı olarak daha yüksek bulunmuştur. Alt grubun ise risk algısı faktöründe bulunan maddelerin her birinden aldığı puan ortalamaları, üst grubun puan ortalamalarından anlamlı olarak daha yüksektir. Elde edilen sonuçlar, İSG Kültürü Ölçeğinde yer alan 19 maddenin her birinin anlamlı derecede ayırt edici olduğunu göstermiştir.

\section{Sonuç}

Bu çalışmada İSG kültürünün değerlendirilebilmesi için bir ölçek geliştirilmiştir. İSG kültürü ölçeği İstanbul ilinde konut inşaatlarında bulunan basit tesadüfi örneklem yoluyla seçilmiş 359 çalışana uygulanmıştır.

İSG Kültürü Ölçeğinin yapı geçerliği için açımlayıcı ve doğrulayıcı faktör analizleri yapılmıştır. AFA sonucunda özdeğeri birin üzerinde üç faktör tespit edilmiştir. Üç faktörden oluşan ölçek toplam varyansın \%57'sini açıklamıştır. Birinci, ikinci ve üçüncü faktör sırasıyla genel iş güvenliği farkındalığı, İSG eğitimi-iletişim ve risk algısı olarak isimlendirilmiştir. Ölçeğinin üç faktörlü yapısının toplanan veriler ile doğrulanıp doğrulanmadığını test etmek için DFA gerçekleştirilmiştir. Ölçeğinin üç faktörlü yapısının toplanan veriler ile genel olarak iyi düzeyde uyum gösterdiği ve ölçeğin üç faktörlü yapısının doğrulandığı anlaşılmaktadır.

Ölçeğin ve ölçek faktörlerinin iç tutarlılığa bağlı güvenirliğinin belirlenmesi adına Cronbach alfa katsayıları 
hesaplanmıştır. Ölçeğinin genel güvenirlik katsayısı (Cronbach's Alpha) $\alpha=0,89$ olarak çok yüksek bir değer olarak belirlenmiştir. $\mathrm{Bu}$ değer ölçeğin genel olarak güvenilir olduğu göstermektedir. Ölçeğin üç faktörü için hesaplanan Cronbach alfa katsayıları da ölçeğin faktörlerinin güvenilir olduğunu göstermektedir

Sonuç olarak bu çalışmada kullanılan analiz yöntemlerinden ortaya çıkan bulgular değerlendirildiğinde 19 madde ve üç faktörden (Genel iş güvenliği farkındalığı, İSG eğitimi-iletişim ve risk algısı) oluşan İSG Kültürü Ölçeğinin kabul edilebilir geçerli bir model olduğu saptanmıştır.

$\mathrm{Bu}$ çalışmada, uygulanan anket ve yapılan analiz sadece inşaat sektöründe bulunan çalışanlar üzerinde yapılmış olup ortaya çıkan sonuçlar araştırmanın sürdürüldüğü katılımcı çalışanlar ile sınırlıdır. Ülkemizdeki tüm sektörler ve çalışma gruplarında güvenirlik ve geçerliliğini gösterebilmek için farklı bölgelerde ve farklı sektörlerde aynı ölçeğin denenmesi gerektiği düşünülmektedir.

\section{Kaynakça}

Alli, B. O., (2001). İş Sağlığı ve Güvenliği Temel Prensipleri. Cenevre, ILO Yayınları.

Balkır, Z., (2012). İş Sağlığı ve Güvenliği Hakkının Korunması: İşverenin İş sağlığı ve güvenliği organizasyonu, Sosyal Güvenlik Dergisi , 56-91s

Browne, M. W., and Cudeck, R., (1993). Alternative ways of assessing model fit. Sage focus editions, 154, 136-136.

Büyüköztürk, Ş., (2007). Sosyal bilimler için veri analizi el kitab1, Pagem Yayınları, Ankara.

Byrne, B., (1989). A Primer of LISREL, Basic Assumptions and Programming for Confirmatory Factor Analysis Models. New York: SSpringer.

Clarke, S., (1999). Perceptions of Organizational Safety: Implications for the Development of Safety Culture. Journal of Organizational Behavior. 20(2): 185-198

Cox S., R. Flin., (1998). "Safety Culture: Philosopher's Stone or Man of Straw?", Work and Stress, 12(3), 189-201.

Çokluk, O., Şekercioğlu, G., ve Büyüköztürk, Ş., (2012). Sosyal bilimler için çok değişkenli istatistik SPSS ve LISREL uygulamaları. Pegem Akademi Yayıncılık. Ankara.

Demircioğlu, M. ve Centel, T., (2003). İş Hukuku. İstanbul, Beta Yayınları.

Dursun, S., (2012). İş Güvenliği Kültürü: Kavram, Modeller ve Uygulama. İstanbul: Beta Yayınevi.

Field, A., (2013). Discovering Statistics Using IBM SPSS (4th ed.). London: Sage Publications.

Guldenmund F.W., (2000). The nature of safety culture: A review of theory and research Safety Science, 34, pp. 215-257 R.M.

Hale A.R. (2000), Culture's confusions Safety Science, 34 (2000), pp. 1-14

Jöreskog, K. G., and Sörbom, D., (1993). LISREL 8: Structural equation modeling with the simplis command language. Lincolnwood: Scientific Software International, Inc.

Misnan, M.S., and Mohammed, A.H., (2007). Development of Safety Culture in The Construction Industry: A Conceptual Framework. In: Boyd, D. ed. Proceedings of the 23rd Annual Conference 2007. September 3-5. Belfast, United Kingdom. pp. 13-22.

McDonald, R. P., and Marsh, H. W., (1990). Choosing a multivariate model: Noncentrality and goodness of fit. Psychological bulletin, 107(2), 247
Olcay, Z. F., Sakalli, A. E., Temur, S., \& Yazici, A. (2021). A study on the shift in fatal construction work-related accidents during the years 2012-2019 in Turkey. International Journal of Occupational Safety and Ergonomics, 1-42.

Olcay, Z. F., Temur, S., \& Sakallı, A. E. (2021). A Research on the knowledge level and safety culture of students taking occupational health and safety course. Cypriot Journal of Educational Science. 16(1), 187-200.

Özdamar, K., (2004). Paket programlar ile istatistiksel veri analizi (çok değişkenli analizler). Kaan Kitabevi, Eskişehir.

Öztürk, T., Caner Akın, G. (2021). Türkiye' de Tüm Sektörlere Ait 2018 Yılı İş Kazalarının ve Kaza Sonucu Yaşam Kaybının Kazazede Yaşı Bakımından Değerlendirilmesi. Avrupa Bilim ve Teknoloji Dergisi, Ejosat, 410-415. DOI: 10.31590/ejosat.867314

Sakallı, A. E. (2019). A tipi ve b tipi kişilik özelliğine sahip bireylerde iş doyumu ve kazalanma arasındaki ilişkinin incelenmesi. Ohs Academy, 2(1), 11-31.

Tabachnick, B. G., \& Fidell, L. S., (2007). Using multivariate statistics (5th ed.). Allyn and Bacon. Boston.

Tanaka, J. S., and Huba, G. J., (1985). A fit index for covariance structure models under arbitrary GLS estimation. British Journal of Mathematical and Statistical Psychology, 38, 197201.

Tavşancıl, E., (2005). Tutumların ölçülmesi ve SPSS ile veri analizi. Nobel Yayıncilık, Ankara.

Temur, S., \& Mertoğlu, B. (2019). Türkiye ve çekya arasındaki güvenlik kültürüne bakış açısı üzerine irdeleme. Ohs Academy, 2(2), 67-76.

Uslu,V., (2014). İşletmelerde İş Güvenliği Performansı ve İş Güvenliği Kültürü Algılamaları Arasındaki İlişki: Eskişehir İli Metal Sektöründe Bir Araştırma,Yüksek Lisans Tezi,Eskişehir Osmangazi Üniversitesi Sosyal Bilimler Enstitüsü,1-94s.

Yaşlığlu, M. M., (2017). Sosyal bilimlerde faktör analizi ve geçerlilik: Keşfedici ve doğrulayıcı faktör analizlerinin kullanılması. İstanbul Üniversitesi İsletme Fakültesi Dergisi, 46, 74-85.

http://www.isigmeclisi.org/site_icerik/2020/10ekim/bedri_tekin. pdf erişim tarihi: $01.03 .20 \overline{2} 1$

http://www.sgk.gov.tr/wps/portal/sgk/tr/kurumsal/istatistik/sgk_i statistik_yilliklari erişim tarihi: 01.03.2021 